\title{
Teaching the literature of the sixteenth-century plague during the Covid-19 pandemic
}

\author{
Aoileann Ni Eigeartaigh \\ Dundalk Institute of Technology, Ireland
}

Keywords: plague; liminality; Elizabethan literature; James Conroy; Humanities; Covid19.

\section{The challenge}

James Conroy argues for the essential role a liminal perspective plays in education. Based on the work of Arnold van Gennep and Victor Turner, liminality is defined by its potential to transcend the limitations of fixed positions. Conroy argues that literature is at its heart a liminal force, using metaphorical language, ambiguity, and imaginative possibilities to suggest alternative perspectives (Conroy, 2004, p.143). The great pleasure of teaching literature at tertiary level is the debate that can be inspired by the close reading of a text. This paper reflects on my teaching on a BA (Hons) Arts programme. Facilitating the exchange of ideas and the new perspectives they can elicit has definitely been the most significant challenge of teaching literature in an entirely online setting, particularly in a sixteenth-century literature module which requires more detailed instruction to dissect and understand the unfamiliar language and concepts. I was concerned that if I focused too much on 'teaching' the texts I would not succeed in encouraging students to adopt an expansive approach to the literature and, moreover, that their lack of familiarity with the context and themes of the sixteenth century, as well as the isolation engendered by their confinement in their separate homes, might make them reluctant to share their thoughts during classes.

In June 2020, Professor Daniel Carey of NUI Galway argued that the Humanities had the potential to make a significant intervention into how a society would deal with the impact of lockdown. Historical and literary accounts of previous crises could assist us in mapping out the future course of our social responses, he explained, while understanding that the 
motivations that drive people to act in particular ways are cited by all public health experts as crucial to defeating the disease (Carey, 2020, cited Conrad, Parsons and McCormick, 2020). Carey's invitation to reflect on the impact of the pandemic on teaching and learning, thus creating the kind of liminal space advocated by Conroy, was central to the decision I made to include a few classes on the literature of the sixteenth-century plague. My hope was that this would facilitate a wider conversation about the ways in which literary texts can intervene in periods of crisis, encouraging students to use their own experiences of lockdown to enhance their engagement with the themes and anxieties expressed by the writers.

\section{The response}

The mid-sixteenth century saw the development of detailed public health measures, with many of the original texts digitally preserved and accessible on websites like nationalarchives.gov.uk. This presented an ideal opportunity to combine an analysis of sixteenth-century texts with a broader contextual examination of the management of the disease and the strategies adopted to encourage public compliance. We examined mortality records, acknowledging that our empathy was significantly increased by our own experience of listening to the daily notifications of Covid-19 deaths published by the Irish government every evening.

We read a number of 'Plague Orders', which outlined a range of mandatory measures, including quarantining, social-distancing, travel restrictions, and enhanced hygiene and sanitation. The extent to which current public health guidelines mirror measures put in place 450 years ago was a source of particular wonder, and students responded enthusiastically to these texts by supplementing material I presented with articles and reports detailing measures they found particularly interesting or onerous. This engagement and desire to use their own experiences to reflect on the Elizabethan texts was very evident in the lively exchanges of information and anecdotes, confirming Conroy's thesis on the success of liminal spaces in developing new perspectives. Although we all missed the immediacy of a face-to-face class, the electronic space certainly facilitated the easy uploading and sharing of information and meant that students could insert their ideas into the discussion in a constructive way by using the chat. 
A significant theme in the Elizabethan period was the conflation of plague and immorality: the plague was widely interpreted as a punishment inflicted on the world by a vengeful God, angry that materialism was replacing spirituality. Some of our liveliest discussions were sparked by reading extracts from such texts, like William Bullein's $A$ dialogue against the fever pestilence (1564), which specifically indicts 'slotishe beastlie people, that kepe their houses and lodgings vnclene' for succumbing to the plague and constituting a threat to 'other cleane bodies'. The disparaging way in which these 'infectious' people are compared to 'clean' people struck a chord with many of the students. We talked a lot about the implications of being 'clean', expanding the literal focus on hygiene to a more ambiguous signifier of moral superiority, drawing on anecdotal evidence that certain groups of people were presumed to be less compliant with public health measures than others and thus blamed for rising case numbers. Many of the students noted that, as younger people, they often felt unfairly singled out by media commentaries. However, they also acknowledged that the othering of minority groups in society, whether defined by age or socio-economic or racial background, was an understandable response, reflective of widespread societal anxiety and perceived lack of control over the spread of the disease.

\section{Recommendations}

Sharon Todd argues that measuring the success of a learning intervention cannot be based on the successful completion of the curriculum alone but must take into account its 'transformative potential', which she defines as the 'small moments of grace, those instants of living transformation (which) actually make a difference to who we as students and teachers become in the process' (Todd, 2014, p.243). The role of education thus transcends the delivery of examinable facts and skills by emphasizing the transformation within one's worldview. The central argument made in this reflection is that examining literary texts written during the sixteenth-century plague can constitute precisely the kind of liminal space we need in order to encourage reflective and transformative perspectives on our current experiences of education during a sustained period of lockdown. The classes in which we spent reading the literature of the plague were among the most enjoyable and fulfilling I had all year. The texts had such resonance for us and provided great insight into the development of public health strategies. The overt blame assigned to the poorer classes in the Elizabethan texts gave us the opportunity to reflect on the prevailing narratives of the current pandemic, and students drew on their frustrations and anxieties to 
really empathise with writers who in many other respects had very different, sometimes incomprehensible, values and priorities to their own.

\section{References}

Bullein, W. (1564) A dialogue against the fever pestilence. Available at:

https://quod.lib.umich.edu/e/eebo/A17158.0001.001?view=toc (Accessed: 22 June 2021).

Conrad, K., Parsons, C. and McCormick Weng, J. (2020) 'Science and the Humanities in the time of pandemic: better together', The Irish Times, 1 June. Available at: https://www.irishtimes.com/culture/books/science-and-the-humanities-in-the-time-ofpandemic-better-together-1.4261769 (Accessed: 22 June 2021).

Conroy, J. C. (2004) Betwixt and between: the liminal imagination, education and democracy. New York: Peter Lang Publishing.

Todd, S. (2014) 'Between body and spirit: the liminality of pedagogical relationships', Journal of Philosophy of Education, 48(2), pp.231-245.

https://doi.org/10.1111/1467-9752.12065.

\section{Author details}

Aoileann Ní Éigeartaigh is a lecturer in English Literature and Culture Studies at Dundalk Institute of Technology. She has published widely in the areas of Irish Literature, American Literature, Feminism and Border Studies, and is the co-editor of three books. She has recently published a number of articles on Northern Irish women writers, feminist adaptations of fairy-tales, and the role of the Humanities during the Covid-19 pandemic. She is editor of Dealga: Irish Journal of Humanities and Social Science Research, the journal of the Department of Humanities at DkIT. 